\title{
Comment
}

\section{O Gestor Escolar e a Dinâmica Democrática na Educação}

\author{
Joeuda Sandra Magalhães Melo ${ }^{1}$
}

Resumo: A implementação de uma gestão escolar democrática é atualmente uma exigência da sociedade, que a entende como um dos possíveis caminhos para uma transformação social, onde a igualdade e o direito para todos aconteçam, de modo que perfil do administrador permita verdadeiras transformações sociais. Nesse sentido, objetivo deste artigo refere-se à necessidade de estudar e conhecer o perfil do gestor escolar na perspectiva educacional atual, analisar a temática da gestão escolar no âmbito estadual, público e privado. A composição desta pesquisa torna-se relevante porque servirá como base fundamental na minha formação como mestranda. A metodologia utilizada para a elaboração deste trabalho consiste na pesquisa bibliográfica realizada a partir de referencias publicada, analisada e discutida como contribuições culturais e cientificas. Ela constitui uma excelente técnica para fornecer ao pesquisador a bagagem teórica, de conhecimento, e o treinamento cientifico que habilitam a produção de trabalhos originais e pertinentes.

Palavras-chave: Administração escolar; Perfil do gestor; Escola publica e privada.

\section{The School Manager and the Democratic Dynamics in Education}

\begin{abstract}
The implementation of a democratic school management is currently a requirement of society that understands it as one of the possible paths to social transformation, where equality and the right for all to happen, so that the administrator profile allows real social change. In this sense, purpose of this article refers to the need to study and know the profile of the school manager in the present educational perspective, examine the issue of school management at the state level, public and private. The composition of this research becomes relevant because it will serve as a fundamental basis of my training as a graduate student. The methodology used for the preparation of this work is the literature survey from references published, analyzed and discussed as cultural and scientific contributions. It is an excellent technique to provide the researcher with theoretical background, knowledge, and scientific training that enable the production of original and relevant work.
\end{abstract}

Keywords: school administration; profile manager; public and private school.

\footnotetext{
${ }^{1}$ Graduada em Educação Física Escolar pela Universidade de Pernambuco-UPE. Pós-Graduada em Educação Física Escolar pela Universidade de Pernambuco-UPE. Mestranda em Ciências da Educação Pela Mestranda pela Anne Sullivan University. E-mail: joeldam,mestrado@yahoo.com.br
} 
Id on Line Revista Multidisciplinar e de Psicologia

Id on Line Multidisciplinary and Psycology Journal

\section{Introdução}

Entende-se por gestão democrática o ato de administrar, gerir uma instituição que promova a participação de todos os atores envolvidos no processo educacional de forma democrática, para que assim ocorra a busca pela melhoria do ensino. Ela vem substituir o autoritarismo empregado durante décadas, envolvendo todos os segmentos sociais que compõem a escola, para proporcionar uma reflexão quanto ao papel do gestor na busca de uma escola pública de qualidade.

A Gestão Democrática na escola é formada por alguns componentes básicos: Constituição do Conselho escolar; Elaboração do Projeto Político Pedagógico de maneira coletiva e participativa; definição e fiscalização da verba da escola pela comunidade escolar; divulgação e transparência na prestação de contas; Avaliação institucional da escola, professores, dirigentes, estudantes, equipe técnica; eleição direta para diretor (a). Vale ressaltar que na cidade de juazeiro essa realidade ainda não é existente no caso de eleições para diretor, acontece somente no âmbito estadual.

Há falta de clareza quanto ao conceito de gestão democrática, porque, tanto nos espaços formais da instituição, como nos espaços informais, percebe-se que há um consenso quanto ao desejo de participar das decisões. O consenso se rompe, no entanto, quando a questão é assumir as responsabilidades destas decisões, pois fica evidenciada a ideia de que quem assume as responsabilidades das decisões é a direção.

É preciso conciliar democracia, liderança, autoridade, confiança e competência, na tentativa de administrar o trabalho de coordenação de tal forma que ele contemple as expectativas advindas dos vários segmentos da escola, tendo como eixo central o comprometimento profissional, calçado na ética e na confiança que no núcleo gestor é depositado.

Um diretor define sua gestão como democrática, porque, segundo ele, permite que os integrantes da comunidade escolar opinem sobre as questões da escola, dando sugestões ou participando das deliberações. Na educação não se concebe a desunião do núcleo gestor, pois o papel do diretor da escola publica municipal, estadual ou particular deve ser viabilizar o trabalho do coordenador tendo em vista a realização de um bom trabalho. 
Percebemos que ainda há muito que evoluir para que de fato possa-se verdadeiramente ter uma gestão democrática de qualidade, a começar por mudanças na sociedade. Cada um fazendo a sua parte através das boas ações em detrimento do bem de todos.

Com intuito de verificar o perfil do administrador escolar nas escolas da rede pública e municipal na cidade de Juazeiro o Norte é que este artigo esta objetivado, seguindo uma metodologia baseada na aplicação de instrumentos de apoio durante a pesquisa.

A revisão da literatura apresentada no trabalho é fruto de pesquisa na área da administração escolar, delineando-se através de tópicos que vão apresentar pressupostos e aparatos a respeito do tema em estudo, como o histórico da administração escolar no Brasil. Característica do gestor na esfera publica e privada, bem como os locais acolhidos para fazer a pesquisa, a metodologia utilizada para a análise dos dados e considerações sobre o processo de mudança ao longo dos anos no que se refere à administração escolar.

\section{A Administração Educacional no Brasil: Aspectos históricos}

O campo da Administração Escolar ou Gestão Escolar, como é abordado na atualidade, teve diversos estudos sistemáticos de educadores brasileiros, no decorrer do século $\mathrm{XX}$, na tentativa de elaborar conceitos teóricos e dar-lhe significado. Estes estudos deram-se pela necessidade emergencial de organização técnica, pedagógica e administrativa nas ações das organizações escolares.

No Brasil o início da história da educação foi marcado e dominado pelos Jesuítas. Teve como fundador Inácio de Loyola, da Companhia de Jesus, que, após um grave ferimento em batalha tornou-se "soldado de Cristo". Os Jesuítas recebiam subsídios do Estado português, este tinha juridicamente, por obrigação, oferecer e formar gratuitamente sacerdotes, bem como oferecer estudo diversificado à população para atender a diversidade de interesses e de capacidades diferenciadas, com propósito de instruir os filhos dos colonos e catequizar os índios à fé católica.

Eis que surge com isso o ensino público financiado pelo Estado e para o Estado, com o objetivo de simplificar os estudos, diversificar os conteúdos e torná-los mais práticos para 
formar indivíduos negociantes que atendessem a interesses do governo. Segundo Ribeiro (2005, p. 33) "foi criado o cargo de diretor geral dos estudos". De acordo com o mesmo autor, esse órgão determinava exames para todos os professores, proibia o ensino público ou particular sem licença do diretor geral dos estudos e designava comissários para o levantamento sob o estado das escolas e dos professores.

Em relação ao novo modelo de organização escolar, poucas mudanças foram feitas, diante das incertezas. Para Ribeiro (2005, p. 34), "pedagogicamente essa nova organização era um retrocesso, mas representou um avanço ao exigir novos métodos". Segundo o mesmo autor, a tradição de formação jesuítica permanece, mas, modernizada e direcionada à elite colonial masculina, prevalecendo à camada dominante portuguesa. Essa compreensão históricofilosófica da história pode possibilitar um melhor entendimento, em que possibilita a contextualização da organização escolar brasileira e, em seu interior, de como se organiza a gestão escolar. Sinteticamente busca-se uma visão da história que tem os seguintes princípios norteadores:

Princípio da determinação material: é o modo de produção da vida material que, em última instância, determina e tornam possível as formas de organização da vida social, inclusive a escola e sua administração. Digo em última instância por que esta determinação não é absoluta, mecânica, mas permeada por contradições, ou, numa palavra, é dialética.

Sobre o princípio da totalidade a organização escolar e, em seu interior, a gestão escolar, constituem partes articuladas do todo econômico, social e político que se inserem, sendo extremamente problemático pressupô-las em si mesmas, isolada e parceladamente, isto é, sem levar em conta o contexto mais amplo que, em grande parte, as determina.

\section{O Administrador de Escolas Públicas}

O conceito de perfil neste trabalho coincide com a ideia de leitura e pesquisa em campo de faces de um fenômeno, representando algo que carrega consigo características gerais desse determinado fenômeno, mostrando os seus modelos distintos. A constituição e compreensão do 
Id on Line Revista Multidisciplinar e de Psicologia

Id on Line Multidisciplinary and Psycology Journal

perfil do administrador escolar se edificam a partir da análise, identificação e caracterização da heterogeneidade com vistas à classificação em grupos mais homogêneos, com a intenção de, a partir desses grupos, conhecer, ainda que não completamente, as especificidades, as diferenças e semelhanças dos gestores escolares.

A gestão nas escolas públicas brasileiras pode ser definidora para o nível de comprometimento do dirigente com a organização e gestão escolar (PINTO, 1994, p.45). Mesmo que isso não se realize de forma tão imediata, aquelas formas podem demonstrar a compreensão que a administração do sistema de ensino tem sobre a função. De forma equivalente, a existência e funcionamento dos conselhos de escola, sabidamente importantes instrumentos da gestão escolar pode nos demonstrar as formas pelas quais os dirigentes escolares os utilizam na condução do processo político que é a gestão escolar.

A escola é uma organização social constituída pela sociedade para cultivar transmitir valores sociais elevados e contribuir para a formação de seus alunos, mediante experiências de aprendizagem e ambiente educacional condizentes com os fundamentos, princípios e objetivos da educação. O seu ambiente é considerado de vital importância para o desenvolvimento de aprendizagens significativas que possibilitem aos alunos conhecerem o mundo e conheceremse no mundo, como condição para o desenvolvimento de sua capacidade de atuação cidadã, mesmo diante das condições de adversidade.

A escolha de diretores escolares é uma ação essencialmente política (DOURADO, 2003, p.68). Seja na adoção das eleições, seja através das indicações, ou seleção, com ou sem concurso público, trata-se sempre de uma ação política. Sabendo-se que o diretor tem a função de coordenar a escola e que decorrem dessa função consequências pedagógicas, institucionais, sociais e especialmente políticas locais, os administradores do sistema de ensino, quando optam por uma daquelas formas, o fazem politicamente com vistas ao que esperam dessas consequências. As relações políticas marcam então, esses processos, como adiante se analisa, ao ponto de se encontrar diferenças que se articulam com as concepções políticas e de educação que os administradores do sistema de ensino tenham. De acordo com o Paro:

O concurso de provas e títulos é considerado por alguns autores como uma das melhores formas de contratação de pessoas para o serviço publico, nele, os candidatos são submetidos a uma prova onde são classificados pelo conhecimento, somados a contagem de seus títulos. (PARO, 2001, p. 45). 
Id on Line Revista Multidisciplinar e de Psicologia

Id on Line Multidisciplinary and Psycology Journal

As indicações para a função de diretor nas redes públicas também podem coexistir com outros modelos, pois podem estar relacionadas com a escolha de dirigentes em escolas novas recém-inauguradas, nas quais ainda não houve tempo hábil para se proceder a eleições, ou nas quais há intervenções do poder público central por diferentes motivos. De qualquer forma, as indicações são, quase sempre, feitas pelos administradores dos sistemas de ensino ou políticos e, por isto, carregam consigo uma forte carga política, uma vez que representam uma intervenção direta do poder público nas escolas ou a utilização da direção escolar como peça do jogo político-partidário cotidianamente executado nas políticas regionais ou locais.

É importante observar que as escolas estaduais possuem mecanismos mais democráticos de escolha dos diretores escolares do que as escolas municipais. Isto tem relação com o fato de que as escolas estaduais adotam as eleições e/ou seleção para a escolha de diretores do que as escolas municipais, que preferem os mecanismos de indicação técnica ou política.

Os municípios são esferas de maior controle político imediato, bem como onde o patrimonialismo parece mais presente (MENDONÇA, 2000, p. 169). Nesse sentido, a indicação de diretores significa a ampliação daquele controle e do domínio patrimonialista da instituição escolar. Isso tem impacto direto nas formas de escolha dos dirigentes escolares, pois ao se proceder a uma indicação, há sempre um pressuposto de que a direção é um cargo político de confiança e, na medida em que os municípios são, normalmente, espaços nos quais a "troca de favores na ocupação do emprego público" (MENDONÇA, 2000, p. 179).

Dentro desse contexto é inegável que nas ultimas décadas educação pública brasileira, em vem se reestruturando em busca de melhores resultados, procurando tornar a escola pública acessível e de qualidade para todos. Contudo, a construção de uma escola em que a participação e a interação sejam uma realidade, depende da ação de todos: dirigentes escolares, professores, estudantes, funcionários, pais de estudantes e comunidade local. Nesse processo, a articulação entre os diversos espaços e mecanismos de participação, como por exemplo: o envolvimento direto do gestor na prática pedagógica docente é fundamental para o exercício do aprendizado democrático que possibilite a formação dos indivíduos críticos, criativos e participativos. Para que se possa caminhar nessa direção faz-se necessário que o aluno se torne ativo e assíduo, 
Id on Line Revista Multidisciplinar e de Psicologia

Id on Line Multidisciplinary and Psycology Journal

visto que essa postura se apresenta como uma dificuldade nos dias atuais dentro do ambiente escolar.

A escola deve ser considerada como um ambiente de vital importância para o desenvolvimento de aprendizagens significativas no sentido de possibilitar aos alunos conhecerem o mundo e conhecerem-se no mundo, como condição para o desenvolvimento de sua capacidade de atuação cidadã, mesmo diante das condições de adversidade. Partindo dessa premissa, a escola é uma organização social constituída pela sociedade para cultivar transmitir valores sociais elevados e contribuir para a formação de seus alunos, mediante experiências de aprendizagem e ambiente educacional condizentes com os fundamentos, princípios e objetivos da educação.

O principal foco da gestão da escola deve ser o desenvolvimento do aluno. Segundo esse princípio, a pedagogia escolar de qualidade é aquela centrada no aluno, que tem o aluno, sua formação e aprendizagem como ponto de partida e de chegada à determinação de todos os planos de ação e avaliação de sua efetividade. A efetivação dessa concepção se processa na escola, a partir da competência profissional dos seus colaboradores, baseada em conhecimentos, habilidades e atitudes relacionados ao nível de desenvolvimento dos alunos envolvidos, sua psicologia e necessidades educacionais, sejam elas coletivas ou específicas.

É inegável que são muitos os desafios enfrentados pelos diretores escolares na atualidade, tendo em vista que é uma imensa responsabilidade estar a frente de ações que envolve bastante experiência e conhecimento sobre o que é de fato gerir uma instituição de ensino, especificamente na rede pública de ensino.

Contudo, observa-se que a educação pública brasileira vem se reestruturando em busca de melhores resultados, procurando tornar a escola pública acessível e de qualidade para todos. Contudo, a construção de uma escola em que a participação e a interação sejam uma realidade, depende da ação de todos os atores escolares. Nesse processo, a articulação entre os diversos espaços e mecanismos de participação, como por exemplo: o envolvimento direto do gestor na prática pedagógica docente é fundamental para o exercício do aprendizado democrático que possibilite a formação dos indivíduos críticos, criativos, reflexivos e participativos. 
Id on Line Revista Multidisciplinar e de Psicologia

Id on Line Multidisciplinary and Psycology Journal

\section{Considerações Finais}

Durante a pesquisa e elaboração deste trabalho, percebemos a necessidade de se ampliar os esforços na construção de escolas cada vez mais democráticas. O perfil do administrador escolar na atual cidade de Juazeiro do Norte frente às expectativas conjunturais, que contribui para a emergência de novos conceitos em educação, nos faz analisar, as diferentes abordagens que influenciam a educação atual, levando em conta as considerações de Ribeiro, Felix e Lück.

As diferentes visões no tocante a administração escolar é de se ampliar o perfil do administrador publico no tocante a adquirir bons resultados frente aos esforços na construção de escolas cada vez mais democráticas. Reconhecendo que a democracia permeia todos os princípios da educação, a comunidade escolar como um todo deve decidir e compartilhar todos os problemas e progressos da instituição escolar.

Sabe-se que a Gestão Democrática é um processo complexo, mas não irrealizável, e que exige de todos os envolvidos (família, profissionais, governo e sociedade), ações imediatas e sólidas que garantam a concretização das ações de um trabalho coletivo, com o propósito de substituir o paradigma de políticas educacionais autoritárias pelo democrático.

Ao longo desta pesquisa percebemos que as escolas da rede publica que fizeram parte deste estudo podem ser consideradas escolas com princípios democráticos, onde os envolvidos neste processo de estrutura organizacional contemporânea de educação voltada para a necessidade dos educandos estejam em consonância com os desejos da comunidade escolar.

Neste sentido, a escola procura mobilizar e articular os que participam desta organização, dando condições necessárias materiais e humanas para que a ação do processo sociopolítico e educacional aconteça da melhor forma possível e com resultados satisfatórios.

Os desafios encontrados devem ser enfrentados tendo em vista a necessidade de inovação para a superação dos problemas encontrados no dia a dia. Desta forma, o diálogo mostra-se como a ferramenta mais eficaz para que os objetivos sejam atingidos. Manter um canal de comunicação aberto entre toda a comunidade escolar torna o ambiente mais tranquilo e útil na hora de resolver conflitos. 
Paro (2001, p.45) diz que "não existem modelos pré-determinados de participação”. É preciso que cada tentativa construa seu próprio caminho "que se faz ao caminhar" refletindo sobre cada passo. A participação é necessária e pressupõe principalmente tomada de decisão, onde a execução é apenas uma consequência, e apresenta vários obstáculos, porém o primeiro requisito é não desistir.

Portanto, por melhor que seja o processo de gestão escolar, pouco valor terá, caso não produzam resultados efetivos para a melhoria da aprendizagem dos alunos. Competências de gestão de resultados educacionais. O dia a dia do gestor, coordenador e secretário está repleto de adversidades, conflitos a serem resolvidos, principalmente nos dias atuais. Nesse contexto, é importante o trabalho participativo e a valorização de novas ideias trazidas pela comunidade escolar, de modo que todos se sintam integrantes do processo educativo.

Os desafios encontrados principalmente nos dias atuais devem ser enfrentados tendo em vista a necessidade de inovação para a superação dos problemas encontrados no dia a dia da escola. Desta forma, o diálogo mostra-se como a ferramenta mais eficaz para que os objetivos sejam atingidos. Manter um canal de comunicação aberto entre toda a comunidade escolar torna o ambiente mais tranquilo e útil na resolução dos problemas.

Ao final deste trabalho, conclui-se que o perfil do administrador da rede publica e privada da cidade de Juazeiro do Norte, é de que são profissionais que trabalham tendo como foco o aluno, no caso do administrador público, independentemente da forma de provimento vislumbra amplas discussões no contexto escolar, no modo como são desenvolvidos os trabalhos pedagógicos devido a tão grande complexidade, e que por isto necessita-se que políticas publicas bem elaboradas sejam colocadas em prática para que assim como a escola da rede privada a pública também consiga alcançar resultados positivos capazes de fazer com que o aluno seja protagonista da transformação social, a qual acredita-se que só através da educação de qualidade possa ser adquirida. 


\section{Referências}

BARBOSA, Filho, F. H. e Pessoa, S. (2006) Educação e Crescimento: o que a evidência empírica e teórica mostram? Instituto Futuro Brasil.

DOURADO, Luiz F. 2000. A escolha de dirigentes escolares: políticas e gestão da educação no Brasil. In FERREIRA, Naura S. C. (org.). Gestão democrática: atuais tendências, novos desafios. São Paulo: Cortez.

FELIX, Ângelo. Planejamento Participativo na Escola: Elaboração, acompanhamento e Avaliação. Petrópolis, RJ: Vozes, 1994.

FIGUEIREDO, A. Pincipios da justiça e avaliação de políticas Lua Nova. Revista de Cultura e Política. 1997, n³ 39, CEDEC

Lei n . 9394, 20 de Dezembro 1996. Lei das Diretrizes e Bases da Educação Nacional. Brasília: MEC, 2006.

MENDONÇA, Erasto F. 2004. A regra e o jogo: Democracia e Patrimonialismo na Educação Brasileira. Campinas: FE/UNICAMP.

PARO Vitor Henrique. Gestão Democrática da Escola Pública. São Paulo: Ática, 2006.p 7. Gestão democrática da escola pública. São Paulo: Ática, 2001. RIBEIRO, José Querino. 1952. Ensaios de uma teoria da administração escolar. São Paulo: USP.

RIBEIRO, Danilo. A Prática do Planejamento Participativo na Escola. SP: Loyola, 1988.

Como citar este artigo (Formato ABNT):

MELO, Joeuda S.M. O Gestor escolar e a Dinâmica Democrática na Educação . Id on Line Revista Multidisciplinar e de Psicologia, Fevereiro de 2017, vol.11, n.34, p. 271-280. ISSN: 1981-1179.

Recebido: 06.01.2017

Aceito: 27.02 .2017 